\title{
Myxofibrosarcoma: Cytomorphologic Findings and Differential Diagnosis on Fine Needle Aspiration
}

\author{
Matthew T. Olson ${ }^{a}$ Syed Z. Ali ${ }^{a, b}$ \\ Departments of a Pathology and ${ }^{b}$ Radiology, The Johns Hopkins Hospital, Baltimore, Md., USA
}

\author{
Key Words \\ Cytomorphologic findings - Fine needle aspiration • \\ Histiocytoma - Malignant fibrous histiocytoma • \\ Myxofibrosarcoma $\cdot$ Myxoid liposarcoma $\cdot$ Myxoid \\ neoplasm $\cdot$ Soft tissue tumor
}

\begin{abstract}
Objective: To analyze the cytomorphologic findings of myxofibrosarcoma (MFS) on fine needle aspiration (FNA) and examine the differential diagnoses. Study Design: A retrospective review was undertaken of material from 22 patients with an FNA procedure of their tumor prior to resection. A tally was performed of all the features known in the literature, including myxoid matrix, spindle cells, nuclear pleomorphism, curvilinear vessels, and multinucleated cells. A review of the literature was also performed to elucidate any advances in the use of morphology and other modalities to deconvolute the challenging differential diagnosis. Clinicoradiologic characteristics and immunostaining were also analyzed and correlated. Results: FNA diagnoses included high-grade sarcoma (32\%), recurrent MFS (23\%), spindle cell neoplasm (18\%), indeterminate-grade sarcoma (14\%), lowgrade sarcoma (9\%), and pleomorphic adenoma (4\%). Of the cases available for morphologic review, myxoid matrix was the most frequent observation ( $88 \%)$, followed by spindle cells $(82 \%)$, nuclear pleomorphism (76\%), multinucleated
\end{abstract}

cells (71\%), and curvilinear vessels (65\%). Myxoid matrix, spindle cells, and nuclear pleomorphism were very often concomitant observations. Conclusion: MFS demonstrates characteristic albeit nonspecific morphological findings and can overlap morphologically with other clinically significant entities based on FNA material.

Copyright $\odot 2012$ S. Karger AG, Basel

\section{Introduction}

Myxofibrosarcoma (MFS) [1] is a soft tissue sarcoma that typically presents on the extremities of adults in their 6th-8th decades. It has previously been called myxoid malignant fibrous histiocytoma (MFH) [2]. The MFS nomenclature now has broad consensus because of the reproducible morphologic appearance and ultrastructure [3]. MFS also portends a better prognosis than the variants of MFH [4-7]. MFS classically presents superficially in the lower extremities, followed by the trunk, upper extremities, neck, and head [1,8-10], but it has also been reported superficially in the breast $[11,12]$, perineum [13], and orbit $[14,15]$. Reports also exist of MFS in deep sites, including the esophagus [16], hypopharynx [17], vocal fold [18], parotid [19], heart [20-22], aorta [23], pulmonary artery [24], lung [25] and brain [26, 27].

\section{KARGER}

Fax +41613061234 E-Mail karger@karger.ch www.karger.com
(C) 2012 S. Karger AG, Basel

$0001-5547 / 12 / 0561-0015 \$ 38.00 / 0$

Accessible online at:

www.karger.com/acy
Correspondence to: Dr. Syed Z. Ali

Departments of Pathology and Radiology, The Johns Hopkins Hospital

600 North Wolfe Street, Room Path 406

Baltimore, MD 21287 (USA)

Tel. +1 410955 1180, E-Mail sali@jhmi.edu 
While different schemes have been developed for grading MFS $[9,28,29]$, there is agreement that the histologic grade is a predictor of metastatic potential [2] and worse survival [8]. Regardless of grade, resection is currently the mainstay of treatment for MFS. Adjuvant radiation plays a role at some institutions because of evidence that it reduces the risk of local recurrence [30, 31], although the published evidence is not unanimous [32, 33]. Reducing local recurrence is a clinically desired outcome both due to the morbidity reduction and the evidence that local recurrences may have a higher grade than the initial neoplasm [22, 34-36].

Because of the aggressive management options, the diagnosis of MFS with fine needle aspiration (FNA) - or at least the placement of the tumor into the spectrum of myxoid neoplasms - can direct the initial clinical treatment and follow-up, especially when the tumor involves the adjacent bone or joint [37]. Despite this need and the fact that MFS is one of the most common soft tissue sarcomas to present in late adulthood $[30,38]$, the cytopathologic features present on FNA have only rarely been described in case reports $[11,39]$ and two other institutional reviews consisting of 13 [40], 12 [41], and $6[42,43]$ patients. This work is a cytohistological correlation of 22 MFS patients seen at The Johns Hopkins Hospital, giving emphasis on cytologic features.

\section{Methods}

\section{Specimen Identification and Cytopathology}

All surgical resections over the last 30 years that were diagnosed as MFS or myxoid MFH were queried to find those cases for which an FNA was obtained prior to surgery. All FNAs were performed under ultrasound guidance with on-site evaluation by an attending cytopathologist or an experienced cytotechnologist. Direct smears were prepared in duplicate as material allowed; one smear was air dried and stained with DiffQuik, and the other was alcohol fixed and stained with the Papanicolaou stain. The median number of 3 passes took place during the FNA procedure (range 1-7), and this yielded a median of 3 DiffQuik- (range 0-7) and 2 Papanicolaou- (range 0-5) stained smears. A cell block was performed in 1 case, and paired core biopsies were performed in 5 cases. These cases were interpreted prospectively by 1 of $8 \mathrm{fac}-$ ulty members who are all board-certified cytopathologists.

\section{Surgical Pathology}

The resection specimens were sectioned and sampled in the standard fashion. They were diagnosed by a different group of pathologists than the cytopathologists who interpreted the FNA biopsies. Immunohistochemistry was not routinely performed on the resection specimens. Grading was assigned prospectively according to the National Cancer Institutes (NCI) grading scheme for soft tissue sarcomas [28].

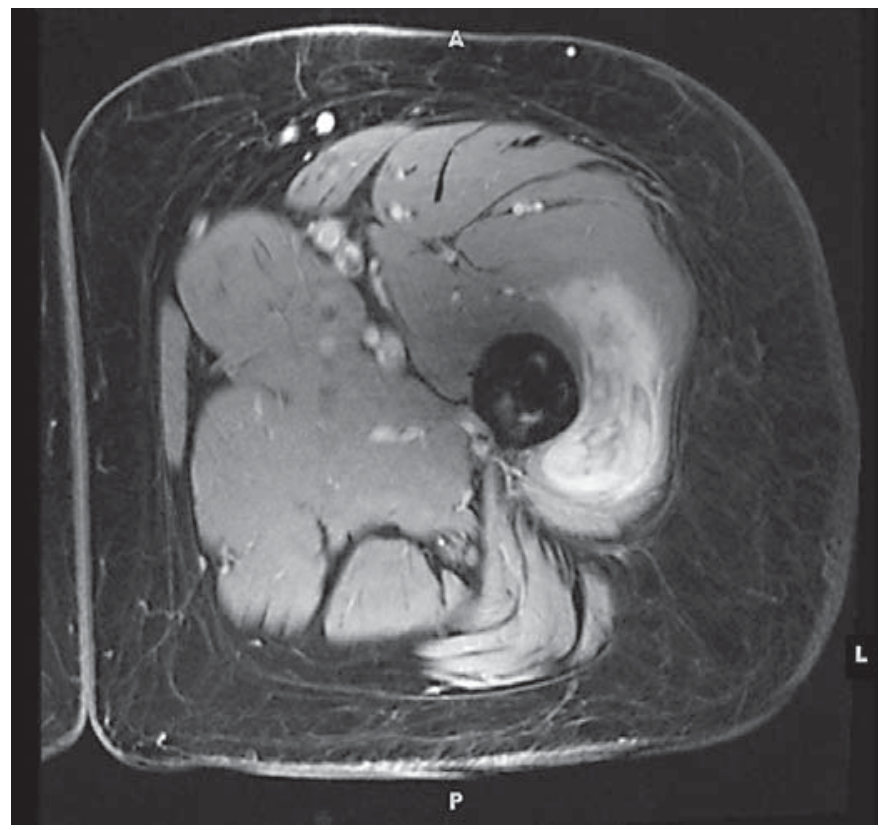

Fig. 1. Radiographically, MFS is best visualized with MRI and typically has a nodular $\mathrm{T}_{2}$-enhancing appearance. This view demonstrates MFS in the thigh.

\section{Retrospective Review}

Seventeen cases from the same number of patients were available for retrospective morphological review. The cases were reviewed looking for the classical features: spindle cells, multinucleate cells, myxoid background, nuclear pleomorphism, and curvilinear vascular structures. Each feature was scored for each case as either present or absent. The histopathology of the resection specimens was also reviewed.

\section{Results}

In our series, we identified 22 patients who had a final resection diagnosis of MFS and had undergone FNA prior to resection. The tumors were seen in both men $(\mathrm{n}=$ $13)$ and women $(n=9)$ with a male/female ratio of $1.4: 1$. The usual clinical manifestation was a painless incidentally discovered mass beneath the skin, although these tumors did present with pain in a subset $(n=3)$ of patients when the mass involved a joint or came into contact with clothing or sites of grooming. The age at first presentation ranged from 38 to 92 years (median 65 years). The demographics, cytologic diagnoses, and ultimate MFS grade from the resection are listed in table 1.

A representative cross-section of the radiology is shown in figure 1 . The tumors in this series were best vi- 


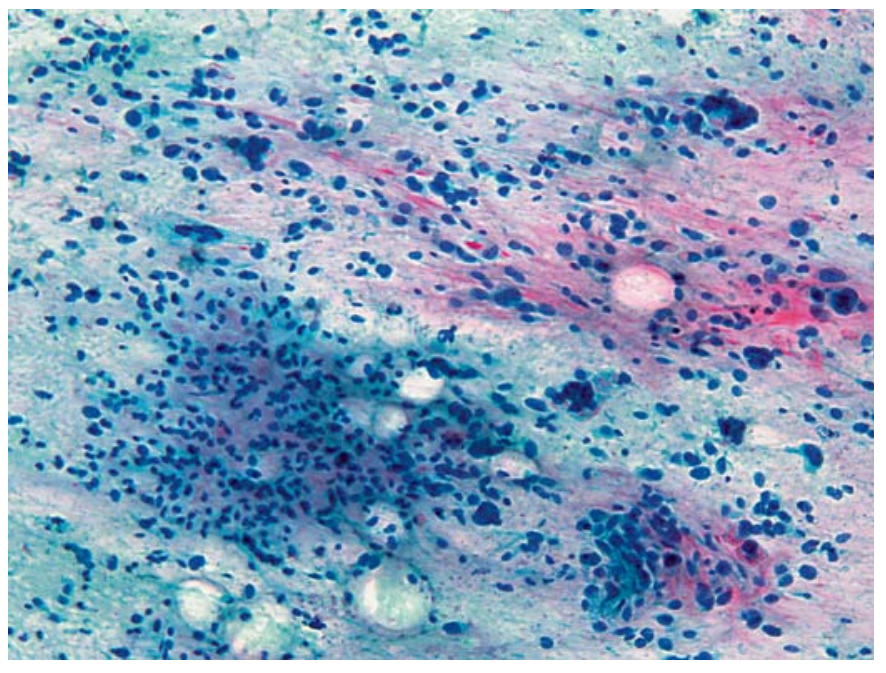

Fig. 2. Smears prepared from FNA of MFS typically show high cellularity at low power $(\times 10$, Papanicolaou stain $)$.

sualized with magnetic resonance imaging (MRI) and were characterized as infiltrating and heterogeneously enhancing nodular septated masses with surrounding edema. The tumor was $T_{2}$ hyperintense with the $T_{1}$ signal usually isointense to muscle. The presenting greatest dimension ranged from 6 to $18 \mathrm{~cm}$ (median $14 \mathrm{~cm}$ ), and the presenting tumor volume ranged from 100 to $1,600 \mathrm{~cm}^{3}$ (median $620 \mathrm{~cm}^{3}$ ).

The majority of MFS cases in this series were grades 2 and 3 on resection. Five (23\%) of these cases were local recurrences; the primary tumors had been excised at other institutions. These cases were the only ones in which the specific diagnosis of MFS was made. Seven cases (32\%) were diagnosed as 'high-grade sarcoma' on FNA, although 'spindle cell neoplasm' (18\%), 'sarcoma' without a grade (14\%), and 'low-grade sarcoma' (9\%) were also used. Seventeen cases were available for morphological review, and a summary of the features demonstrated on review of the FNA material is given in table 2. Immunohistochemistry was performed on the FNA material of only 1 case. It was not immunoreactive for $\mathrm{S} 100$ protein or AE1/AE3.

In general, FNA from MFS was cellular on low power (fig. 2). The most prominent features included myxoid matrix (fig. 3), spindle cells, nuclear pleomorphism (fig. 4), multinucleated cells (fig. 5), and curvilinear vascular structures (fig. 6). Myxoid material is prominent in $88 \%$; its absence had the tendency to discourage the placement of the tumor into the realm of myxoid neoplasms unless the patient had a known history of MFS. Our mor-
Table 1. Demographics, body site, grade, and FNA interpretation for 22 MFS cases

\begin{tabular}{lllll}
\hline Age & Sex & Location & FNA & Grade \\
\hline 51 & M & thigh & LGS & 1 \\
81 & M & cervical spine & PA & 1 \\
47 & F & calf & UGS & 2 \\
50 & F & thigh & HGS & 2 \\
50 & F & thigh & HGS & 2 \\
50 & M & axilla & SCN & 2 \\
51 & M & calf & MFS & 2 \\
56 & F & forearm & UGS & 2 \\
56 & F & thigh & UGS & 2 \\
61 & M & thigh & SCN & 2 \\
63 & M & calf & HGS & 2 \\
67 & F & calf & MFS & 2 \\
69 & F & thigh & HGS & 2 \\
68 & M & thigh & MFS & 2 \\
78 & M & lumbar spine & LGS & 2 \\
82 & M & calf & HGS & 2 \\
38 & F & chest wall & SCN & 3 \\
67 & M & calf & MFS & 3 \\
67 & M & prostate & MFS & 3 \\
73 & F & thigh & SCN & 3 \\
78 & M & thigh & HGS & 3 \\
92 & M & forearm & HGS & 3 \\
\hline
\end{tabular}

LGS = Low-grade sarcoma; PA = pleomorphic adenoma; UGS = ungraded sarcoma; HGS = high-grade sarcoma; $\mathrm{SCN}=$ spindle cell neoplasm; MFS = recurrent MFS.

Table 2. Counts listed for the morphological features in the 17 cases of MFS available for morphological review

\begin{tabular}{ll}
\hline Feature & Cases, $\mathrm{n}$ \\
\hline Myxoid matrix & $15(88 \%)$ \\
Spindle cells & $14(82 \%)$ \\
Nuclear pleomorphism & $13(76 \%)$ \\
Multinucleated cells & $12(71 \%)$ \\
Curvilinear vessels & $11(65 \%)$ \\
\hline
\end{tabular}

phological examination has revealed 12 cases with abundant large multinucleated cells. This review contains a predominance of grades 2 and 3 MFS, so the finding of multinucleated cells is somewhat expected. Review of the 2 cases of grade 1 MFS failed to show multinucleated cells. Conversely, all cases of grade 3 and $80 \%$ of grade 2 MFS showed numerous multinucleated cells.

Given the high percentage of cases that contained more than one feature, the number of coexistent features as well as specific features that occurred together was 


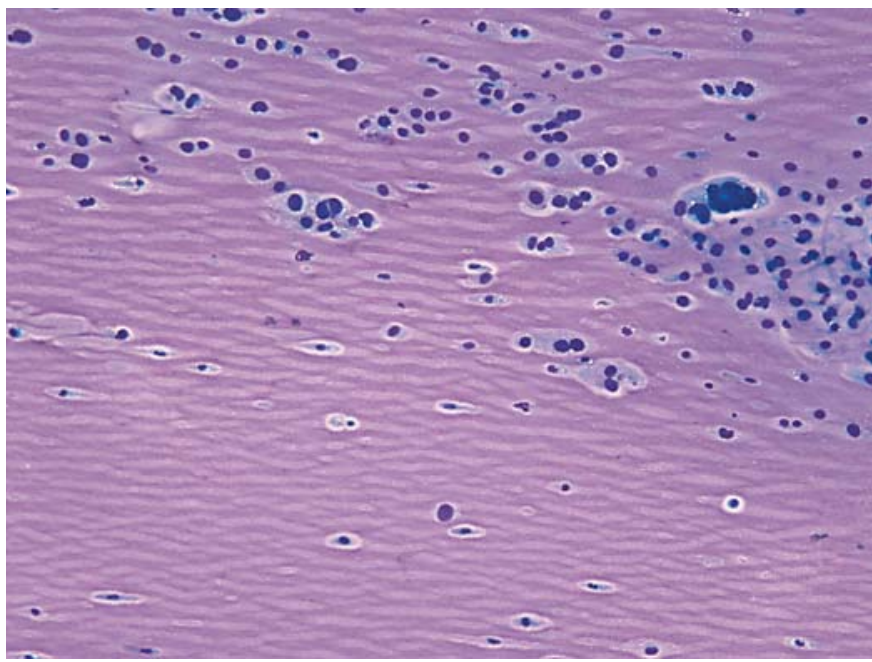

Fig. 3. When it is present, the myxoid matrix from MFS is usually copious ( $\times 10$, DiffQuik stain).

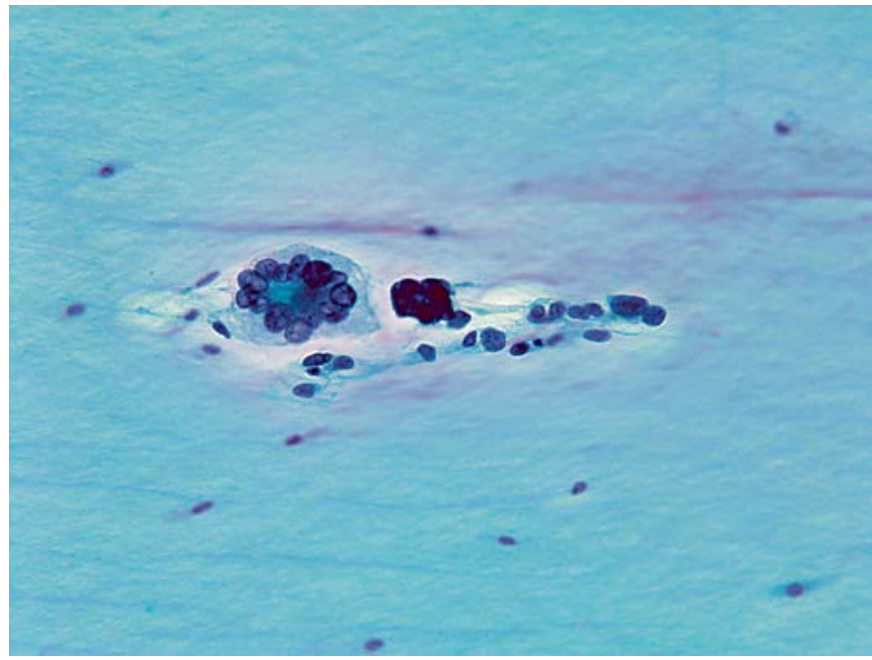

Fig. 5. Multinucleated cells are a common finding in MFS $(\times 40$, Papanicolaou stain).

examined (fig. 7). Interestingly, only 1 case demonstrated spindle cells alone, and this had been called 'spindle cell neoplasm' at the time of sign-out. The case that demonstrated only 2 features was erroneously diagnosed as 'pleomorphic adenoma' due to its placement in the upper neck. The majority of cases demonstrated three or more of the classic but nonspecific features. Not surprisingly, when the findings were examined for specific features

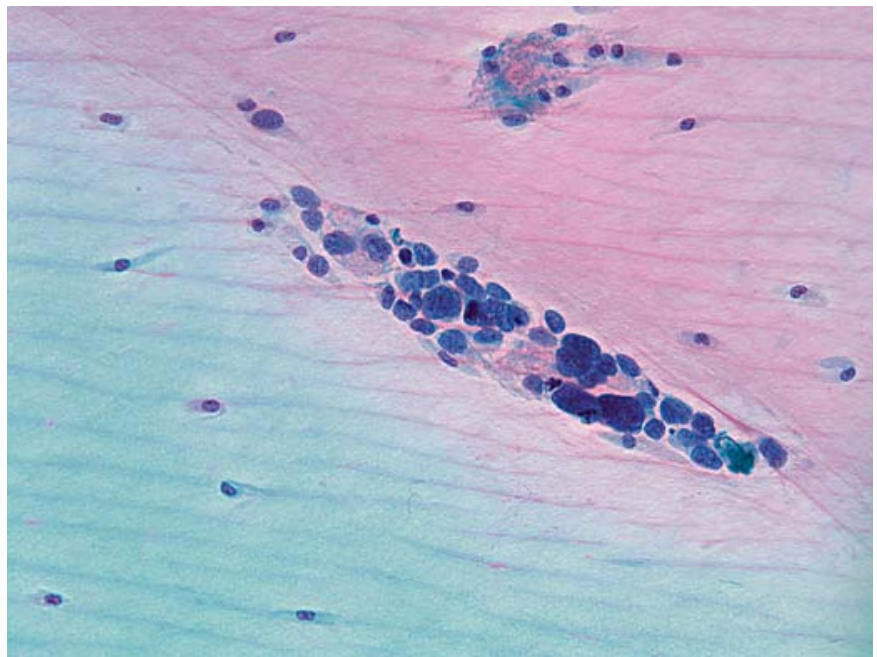

Fig. 4. MFS often demonstrates a spectrum of nuclear shapes ranging from spindle-shaped to ovoid $(\times 20$, Papanicolaou stain).

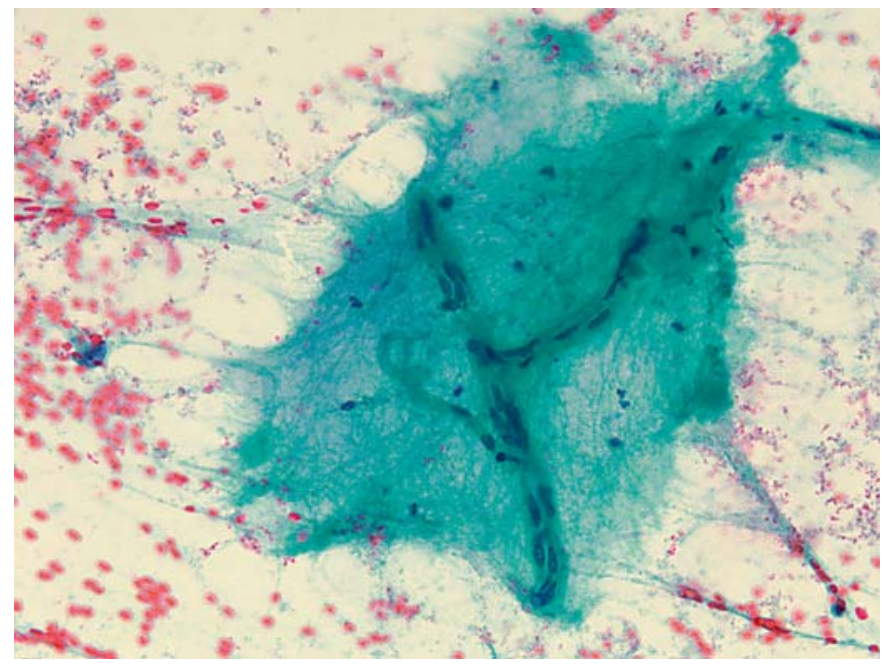

Fig. 6. The curvilinear blood vessels in MFS can be present as small segments or, as in this case, in large fragments ( $\times 10$, Papanicolaou stain).

that demonstrated concomitant observations (fig. 7b), the typical image emerged of a smear with myxoid matrix, nuclear pleomorphism, and spindle cells. Spindle cells had a high level of co-observation with both nuclear pleomorphism and multinucleated cells. Interestingly, the two least frequent observations - multinucleated cells and curvilinear vessels - had a very high rate of coobservation. 


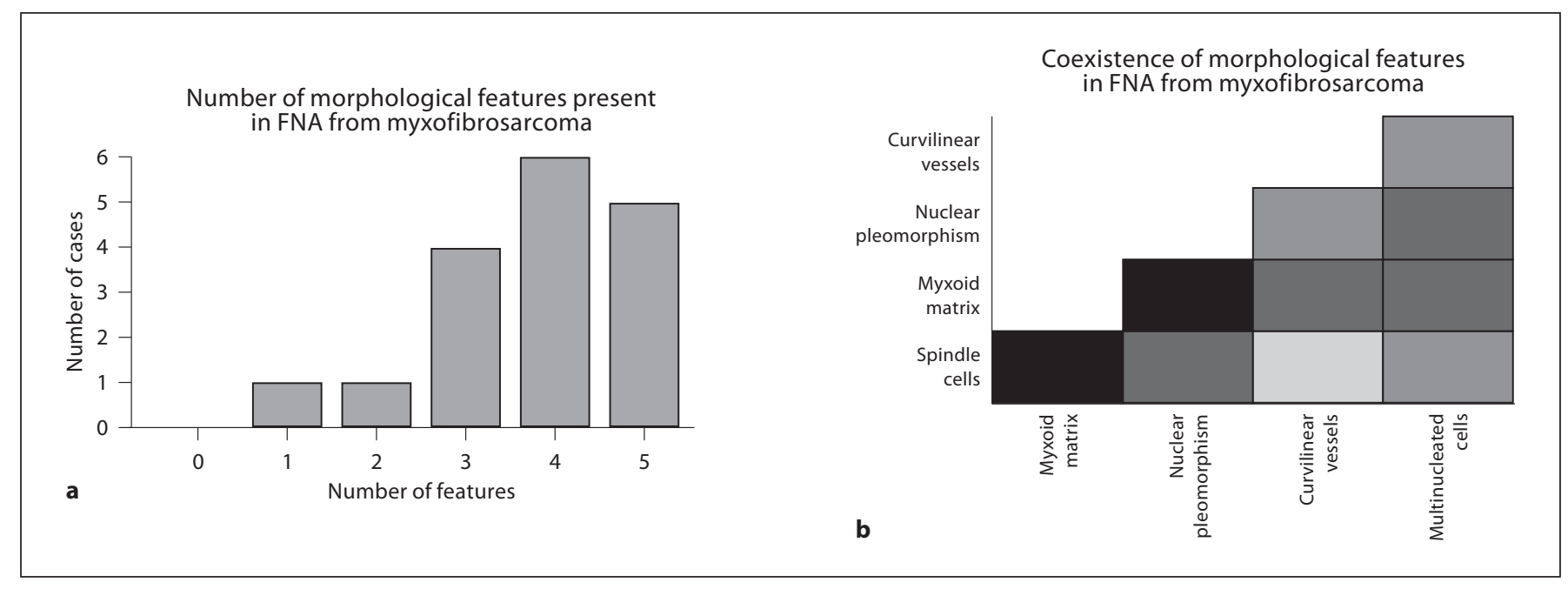

Fig. 7. The number of the five MFS features (myxoid matrix, spindle cells, nuclear pleomorphism, curvilinear vessels, and multinucleated cells) that was observed in the FNA cases is plotted in a. Co-observation of two features is plotted in b. More co-observed features have darker intersections.

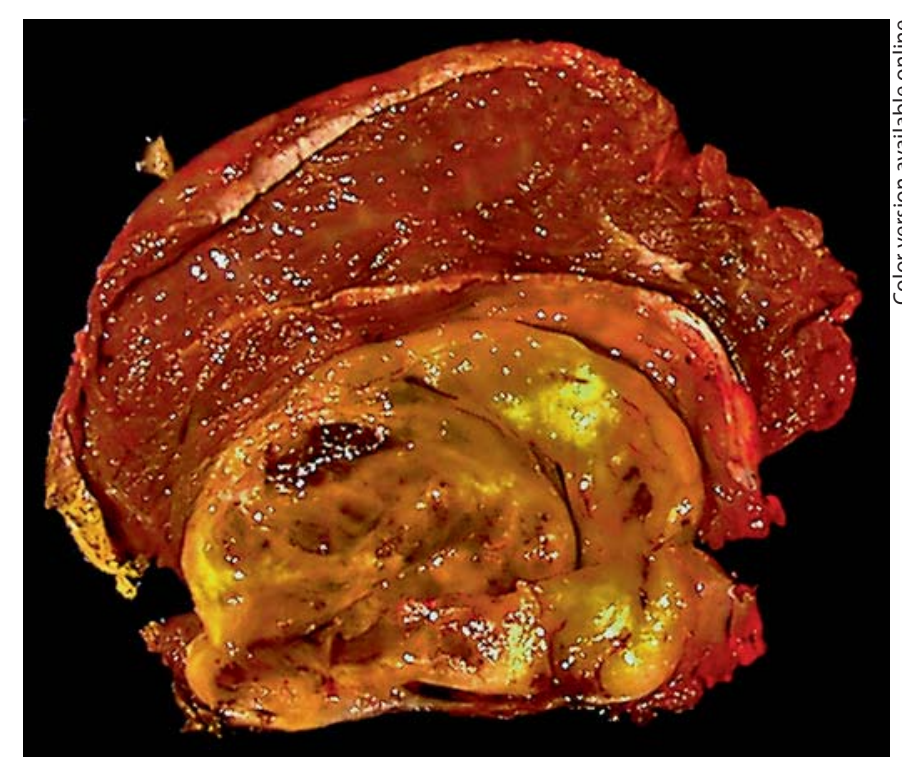

Fig. 8. Gross cross-section of the resection specimen. The tumor is invading the vastus lateralis muscle.

Upon resection, the gross appearances of these tumors were described as heterogeneous and nodular with variable and scattered pockets of grossly apparent matrix. A representative cross-section from a resection of MFS in the vastus lateralis is shown in figure 8. Histologically, MFS resections demonstrated all of the features that were

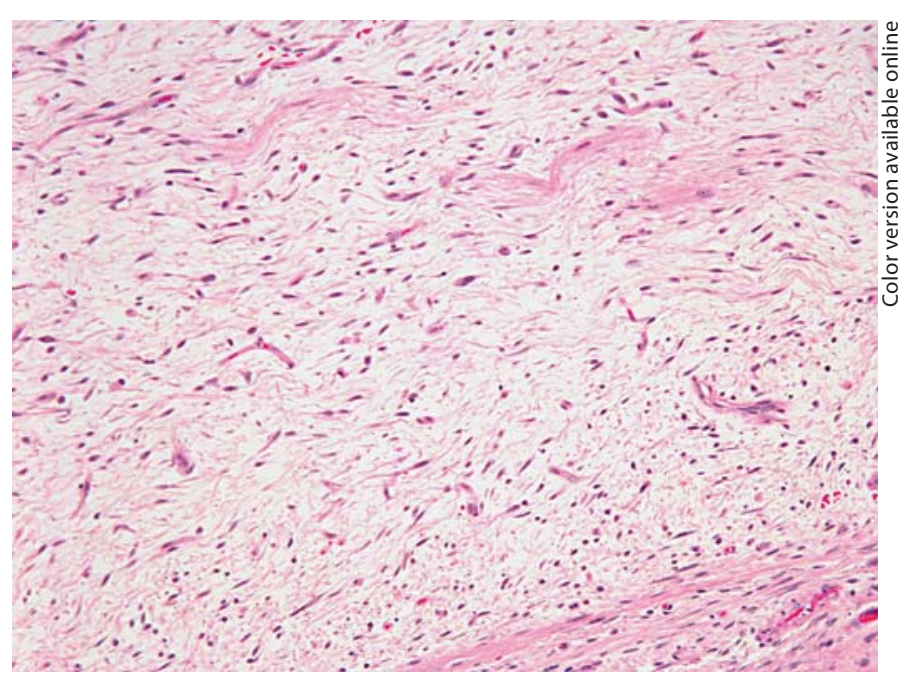

Fig. 9. Histopathology from a low-grade MFS resection specimen with myxoid matrix and predominantly spindle-shaped cells with some epithelioid cells. Curvilinear vascular structures can also be seen in this field.

apparent on cytopathology - including curvilinear vessels, spindle cells, nuclear pleomorphism, and myxoid matrix. An example of the histology seen in a low-grade MFS is shown in figure 9. 


\section{Differential Diagnosis}

The myxoid variant of nodular fasciitis (MNF) [44] is an important diagnostic consideration because it is benign and often self-limiting, so does not always require excision [45]. The morphologic overlap between MNF and MFS can be high because both demonstrate myxoid matrix, spindle cells, and a high degree of anisonucleosis. To aid in distinguishing these two lesions, MNF is a faster growing lesion, so it typically presents with pain at a smaller size. Additionally, the nuclei of MNF usually have prominent nucleoli, and the mitotic rate is higher in MNF than in MFS [46]. If it is possible, immunohistochemistry can be useful since the MNF labels with stains for smooth muscle actin and histiocyte markers, while MFS has not been shown to do this [47].

The distinction between MFS and myxoid liposarcoma (MLS) is clinically useful because MLS is susceptible to traditional and experimental chemotherapeutic regimens $[48,49]$. This is often difficult on FNA material alone. In an FNA study on MLS [50], cytologic preparations of this tumor were found to contain a less prominent vascular network and vacuolization in the tissue fragments. MLS also demonstrates more cellular uniformity. The cellular uniformity in MLS is the most important feature as it is commensurate with the observation that MLS is associated with translocations: primarily the $\mathrm{t}(12 ; 16)$ (q13;p11) translocation [51-53] and less commonly the $t(12 ; 22)(q 13 ; q 12)$ translocation $[54,55]$. MFS is not associated with clonal translocations [56, 57]; some tumors even have normal karyotypes [36].

Because of the similarity in nomenclature and occasionally overlapping histological appearance, MFS can be confused with low-grade fibromyxoid sarcoma (LGFMS) [58, 59]. MFS and LGFMS differ epidemiologically; LGFMS typically presents 10-20 years earlier than MFS, which classically presents in the 6th-8th decades. These entities can often be separated morphologically because LGFMS is poorly vascularized, so does not typically exhibit curvilinear vessels. Additionally, the nuclei of LGFMS are not as pleomorphic as those of MFS [60]. There is a paucity of solid qualitative immunohistochemical differences between these two entities $[9,61]$. While one publication demonstrates quantitative immunohistochemical differences in cell cycle markers between these two tumors [10], the practical use of these for distinguishing between LGFMS and MFS - especially on cytologic preparations - is dubious. LGFMS is associated with the $t(7 ; 16)(q 34 ; p 11)$ translocation [62], which has not been shown in MFS [63]. Another translocation-associ- ated sarcoma, extraskeletal myxoid chondrosarcoma (EMCS), is often separated from MFS with light microscopy alone because of the arrangement of EMCS cells into cohesive cords and the characteristic lacunar appearance. EMCS has stereotyped cytogenetic translocations; classically EMCS harbors $t(9 ; 22)(\mathrm{q} 22, \mathrm{q} 12)[64,65]$, although $\mathrm{t}(9 ; 17)(\mathrm{q} 22 ; \mathrm{q} 11)[66]$ and $\mathrm{t}(9 ; 15)(\mathrm{q} 22 ; \mathrm{q} 21)$ [67] have also been reported. Although very rare, chordoma periphericum can be placed in the differential diagnosis as it contains myxoid matrix $[40,68]$. The physaliferous cells arranged in chords and immunoreactivity for cytokeratin stains are helpful features in making this diagnosis and distinguishing it from MFS.

Intramuscular myxoma (IM) is a diagnostic consideration. The two entities can be difficult to separate with FNA based on morphology alone [69]. As MFS can invade muscle, and myxoma can spread superficially, location is not always helpful in separating these two entities [70]. Histologically, IM is a poorly vascularized tumor as opposed to MFS, in which the curvilinear vasculature is often prominent. The distinction is important because IM has a benign natural history with a low risk for recurrence and metastasis [71]. Molecular analyses have shown that IM - but not MFS - harbors the activating missense GNAS1 mutation on codon 201 [72, 73], although the data about the diagnostic value of this mutation are currently inadequate. Myxoid neurofibroma is another consideration. Morphologically, myxoid neurofibroma has collagen fibrils intermixed with the spindle cells and should have less nuclear pleomorphism than MFS. If it is possible, immunohistochemistry is helpful in making this distinction as myxoid neurofibroma labels with the immunohistochemical stain for S100 protein [74]. Myoepithelial tumors of soft tissue can have the same clinical presentation as MFS. Cytopathologic and histopathologic division of these two entities can be challenging as they both exhibit variable amounts of myxoid matrix, pleomorphic epithelioid cells, and spindle cells. Myoepithelial tumors of soft tissue can demonstrate other epithelial or metaplastic features, such as ducts, clear cells, or cartilage, and when these are present they are helpful. Myoepithelial tumors of soft tissue are immunohistochemically distinct from MFS. They are particularly immunoreactive for cytokeratins, S100 protein, and calponin [75].

Vascular tumors with myxoid features, such as pleomorphic hyalinizing angiectatic tumor, and angiomyxoma can present subcutaneously and in the same anatomical distribution as MFS. Histological overlap including myxoid material and variable nuclear pleomorphism can lead to diagnostic confusion with pleomorphic hyalin- 
izing angiectatic tumor [76-78]. The classic features supporting the latter diagnosis, such as extensive hyalinization, vascular ectasia, and hemosiderin-laden macrophages are nonspecific. Furthermore, it is not clear from the literature or our experience how well the vascular hyalinization or ectasia would be appreciated on FNA material. Similarly, the curvilinear blood vessels and myxoid material can also lead to confusion with angiomyxolipoma [79] and angiomyxoma [80, 81]. The lipid droplets in angiomyxolipoma could be helpful in supporting this diagnosis. Angiomyxoma tends to have more vascular telangiectasia and less morphological heterogeneity than MFS. While immunohistochemical data in all of these contexts are lacking, it seems reasonable that a lack of CD34 staining in the neoplastic cells would support the diagnosis of MFS.

High-grade MFS can overlap morphologically with spindle cell melanoma [82], but immunohistochemistry for any of the melanoma markers would provide resolution. When the MFS is of high grade, it is often not possible to separate it from pleomorphic sarcoma because both these entities demonstrate high cellularity, a high degree of nuclear pleomorphism, and generally low amounts of myxoid material $[43,83]$. There is usually not a consequence to making this distinction with current management options [84]. When it is present, myxoid matrix is a helpful cue that the tumor is a high-grade MFS. However, as little as $10 \%$ of sections from a highgrade MFS may show myxoid matrix $[9,85]$. This is a relevant detail in two commonly encountered clinical scenarios. First, MFS commonly presents at a high grade, and the myxoid matrix may not be sampled with the FNA procedure. Second, in the FNA of recurrent MFS, lack of myxoid matrix is perfectly consistent with a recurrence given that the grade often advances, and high-grade tumors have low amounts of matrix.

\section{Discussion}

The diagnostic sensitivity of prominent myxoid material for making the classification of a myxoid neoplasm on FNA material is dubious based on these data given the observation that only $88 \%$ of our cases demonstrated prominent myxoid material. In several cases, the myxoid stroma was very thin and difficult to appreciate. The 2 cases that did not show myxoid material were both of high grade on resection. This finding agrees with previous investigations that have linked scant myxoid matrix with a higher grade.

Myxofibrosarcoma on FNA
Three entities that demonstrate substantial morphological overlap with MFS - MLS, EMCS, and LGFMS are translocation-associated sarcomas. A fluorescent in situ hybridization probe has been developed [86] that detects the most common translocations associated with these tumors, and this was deployed retrospectively in a small number of tumors with success. It remains to be demonstrated if these translocations are beneficial in prospective diagnostic analysis. If such an approach does lead to a clinically useable assay, MFS would be a genetic diagnosis of exclusion with the current available research because it is too complex to categorize with translocations or single mutations. In other developments, one investigator has used mass spectrometry and immunohistochemistry to detect differences in the specific collagen and proteoglycan composition of the extracellular matrices of EMCS and MFS [87] as well as IM and MFS [73]. While these data are preliminary, their potential for offering a secondary means of categorizing myxoid tumors is significant [88]. It remains to be demonstrated if these same changes are common for large numbers of tumors or if the same tools can be used to differentiate MFS from other myxoid tumors and if this approach is robust in prospective diagnostic endeavors.

The use of FNA for soft tissue neoplasms varies significantly among institutions. As the procedure is inexpensive and carries little risk, it has been shown to carry some desirable features as a first-line diagnostic modality for assessing lesions of this type [43]. The two major drawbacks are the difficulty in separating MFS from other myxoid neoplasms and the inability of FNA material to provide a grade for MFS. As discussed, the myxoid neoplasms demonstrate different morphological features, but these are nonspecific; morphology can only take the diagnosis so far. Indeed, as our own data show, the specific diagnosis of MFS was only made in cases of local recurrence. However, given recent advances in the cytogenetic and molecular understanding of the other myxoid tumors, FNA appears more ideally suited than ever as a diagnostic modality for myxoid neoplasms. While a clinical trial has yet to be performed, one could envision a practice whereby on-site evaluation was used to direct the appropriate complement of molecular and biochemical assays that could rapidly lead to the correct diagnosis and follow-up management. The challenge of deciphering a high-grade MFS from pleomorphic sarcoma is one that is not likely to be resolved without further advances in molecular diagnostics, but this distinction would be difficult to make on core biopsy and would lead to the same management: resec-

Acta Cytologica 2012;56:15-24 
tion. Thus, this ambiguity in the diagnosis need not be a deterrent for pursuing FNA in the workup of a soft tissue tumor.

\section{Conclusion}

In conclusion, FNA interpretation of myxofibrosarcoma can be challenging since the cytopathologic findings overlap those of numerous other entities. However, the placement of the tumor into the spectrum of myxoid neoplasm is realistic with the morphologic findings. Advances in the molecular characterization of myxoid neoplasms appear to provide the necessary specificity to distinguish between the entities within the differential diagnosis. If the combination between morphology and molecular methods accomplishes this task, FNA could provide the ideal diagnostic procedure for the initial workup of soft tissue neoplasms.

\section{References}

1 Angervall L, Kindblom LG, Merck C: Myxofibrosarcoma. A study of 30 cases. Acta Pathol Microbiol Scand A 1977;85A:127-140.

2 Weiss SW, Enzinger FM: Myxoid variant of malignant fibrous histiocytoma. Cancer 1977;39:1672-1685.

3 Kindblom LG, Merck C, Angervall L: The ultrastructure of myxofibrosarcoma. A study of 11 cases. Virchows Arch A Pathol Anat Histol 1979;381:121-139.

4 O’brien J, Stout A: Malignant fibrous xanthomas. Cancer 1964;17:1445-1455.

5 Weiss SW, Enzinger FM: Malignant fibrous histiocytoma: an analysis of 200 cases. Cancer 1978;41:2250-2266.

6 Enzinger FM: Malignant fibrous histiocytoma 20 years after Stout. Am J Surg Pathol 1986;10(suppl 1):43-53.

$\checkmark 7$ Fletcher CD, Gustafson P, Rydholm A, Willén $\mathrm{H}$, Akerman $\mathrm{M}$ : Clinicopathologic reevaluation of 100 malignant fibrous histiocytomas: prognostic relevance of subclassification. J Clin Oncol 2001;19:3045-3050.

-8 Merck C, Angervall L, Kindblom LG, Odén A: Myxofibrosarcoma. A malignant soft tissue tumor of fibroblastic-histiocytic origin. A clinicopathologic and prognostic study of 110 cases using multivariate analysis. Acta Pathol Microbiol Immunol Scand Suppl 1983;282:1-40.

-9 Mentzel T, Calonje E, Wadden C, Camplejohn RS, Beham A, Smith MA, Fletcher CD: Myxofibrosarcoma. Clinicopathologic analysis of 75 cases with emphasis on the low-grade variant. Am J Surg Pathol 1996;20:391-405.

10 Oda Y, Takahira T, Kawaguchi K, Yamamoto H, Tamiya S, Matsuda S, Tanaka K, Iwamoto Y, Tsuneyoshi M: Low-grade fibromyxoid sarcoma versus low-grade myxofibrosarcoma in the extremities and trunk. A comparison of clinicopathological and immunohistochemical features. Histopathology 2004; 45:29-38.

-11 Klopcic U, Lamovec J, Luzar B: Fine needle aspiration biopsy of primary breast myxofibrosarcoma: a case report. Acta Cytol 2009; 53:109-112.
12 Hocevar M, Marinsek ZP, Zidar A: Myxofibrosarcoma of the breast as an unusual variant of malignant fibrous histiocytoma: report of a case. Surg Today 2004;34:752-754.

13 Mourra N, Hoeffel C, Gaujoux S, Coindre J-M, Flejou J-F: Myxoid perineal tumour in a 25 -year-old woman. Histopathology 2006; 49:533-536.

14 Wang M, Khurana RN, Parikh JG, Hidayat AA, Rao NA: Myxofibrosarcoma of the orbit: an underrecognized entity? Case report and review of the literature. Ophthalmology 2008;115:1237-1240.e2.

-15 Zhang Q, Wojno TH, Yaffe BM, Grossniklaus HE: Myxofibrosarcoma of the orbit: a clinicopathologic case report. Ophthal Plast Reconstr Surg 2010;26:129-131.

16 Song HK, Miller JI: Primary myxofibrosarcoma of the esophagus. J Thorac Cardiovasc Surg 2002;124:196-197.

17 Nishimura G, Sano D, Hanashi M, Yamanaka S, Tanigaki Y, Taguchi T, Horiuchi C, Matsuda H, Mikami Y, Tsukuda M: Myxofibrosarcoma of the hypopharynx. Auris Nasus Larynx 2006;33:93-96.

18 Gugatschka M, Beham A, Stammberger H, Schmid C, Friedrich G: First case of a myxofibrosarcoma of the vocal folds: case report and review of the literature. J Voice 2010;24: 374-376.

19 Li X, Chen X, Shi Z-H, Chen Y, Ye J, Qiao L, Qiu J-H: Primary myxofibrosarcoma of the parotid: case report. BMC Cancer 2010;10: 246.

-20 Lazaros GA, Matsakas EP, Madas JS, Toli DI, Nikas DJ, Kershaw MA, Alpert MA: Primary myxofibrosarcoma of the left atrium: case report and review of the literature. Angiology 2008;59:632-635.

21 Heletz I, Abramson SV: Large obstructive cardiac myxofibrosarcoma is nearly invisible on transthoracic echocardiogram. Echocardiography 2009;26:847-851.
22 Kwong RA, Kossard S: Histopathological evolution of a cutaneous myxofibrosarcoma. Australas J Dermatol 2008;49:169-172.

-23 Dang D, Rosado-de-Christenson ML, Suster SM: Primary aortic myxofibrosarcoma mimicking thrombus: findings on CT, MRI, and angiography. J Thorac Imaging 2009;24: 125-128.

-24 Tavora F, Miettinen M, Fanburg-Smith J, Franks TJ, Burke A: Pulmonary artery sarcoma: a histologic and follow-up study with emphasis on a subset of low-grade myofibroblastic sarcomas with a good long-term follow-up. Am J Surg Pathol 2008;32:1751-1761.

-25 Hasanoğlu HC, Karalezli A, Tanrıverdio E, Gümüs M, Aydın M: A mass of myxofibrosarcoma in the lung. Tuberk Toraks 2011;59: 73-76.

26 Krishnamurthy A, Vaidhyanathan A, Majhi $\mathrm{U}$ : Myxofibrosarcoma of the infratemporal space. J Cancer Res Ther 2011;7:185-188.

27 Kuo J-R, Chio C-C, Wang C-C, Chu Y-H, Lin K-C, Chuang S-S: Radiation-induced intraand extra-cranial high-grade myxofibrosarcoma with tumor bleeding. J Clin Neurosci 2008;15:1151-1154

28 Costa J, Wesley RA, Glatstein E, Rosenberg SA: The grading of soft tissue sarcomas. Results of a clinicohistopathologic correlation in a series of 163 cases. Cancer 1984;53:530-541.

29 Trojani M, Contesso G, Coindre JM, Rouesse J, Bui NB, de Mascarel A, Goussot JF, David M, Bonichon F, Lagarde C: Soft-tissue sarcomas of adults; study of pathological prognostic variables and definition of a histopathological grading system. Int J Cancer 1984;33: 37-42.

30 Gronchi A, Lo Vullo S, Colombo C, Collini P, Stacchiotti S, Mariani L, Fiore M, Casali PG: Extremity soft tissue sarcoma in a series of patients treated at a single institution: local control directly impacts survival. Ann Surg 2010;251:506-511.

31 Mutter RW, Singer S, Zhang Z, Brennan MF, Alektiar KM: The enigma of myxofibrosarcoma of the extremity. Cancer 2011, E-pub ahead of print. 
32 Haglund KE, Raut CP, Nascimento AF, Wang Q, George S, Baldini EH: Recurrence patterns and survival for patients with intermediate- and high-grade myxofibrosarcoma. Int J Radiat Oncol Biol Phys 2010, E-pub ahead of print.

- 33 Sanfilippo R, Miceli R, Grosso F, Fiore M, Puma E, Pennacchioli E, Barisella M, Sangalli C, Mariani L, Casali PG, Gronchi A: Myxofibrosarcoma: prognostic factors and survival in a series of patients treated at a single institution. Ann Surg Oncol 2011;18:720-725.

- 34 Ferguson PC, Deshmukh N, Abudu A, Carter SR, Tillman RM, Grimer RJ: Change in histological grade in locally recurrent soft tissue sarcomas. Eur J Cancer 2004;40:2237-2242.

- 35 Fukunaga M, Fukunaga N: Low-grade myxofibrosarcoma: progression in recurrence. Pathol Int 1997;47:161-165.

- 36 Willems SM, Debiec-Rychter M, Szuhai K, Hogendoorn PCW, Sciot R: Local recurrence of myxofibrosarcoma is associated with increase in tumour grade and cytogenetic aberrations, suggesting a multistep tumour progression model. Mod Pathol 2006; 19: 407-416.

- 37 Kaya M, Wada T, Nagoya S, Yamashita T: Bone and/or joint attachment is a risk factor for local recurrence of myxofibrosarcoma. J Orthop Sci 2011;16:413-417.

38 Mentzel T: Sarcomas of the skin in the elderly. Clin Dermatol 2011;29:80-90.

39 Weber MH, Kilpatrick SE, Bergman S: The cytologic diagnosis of epithelioid myxofibrosarcoma: a case report. Diagn Cytopathol 2010, E-pub ahead of print.

40 Merck C, Hagmar B: Myxofibrosarcoma: a correlative cytologic and histologic study of 13 cases examined by fine needle aspiration cytology. Acta Cytol 1980;24:137-144

41 Colin P, Lagacé R, Caillaud J-M, Sastre-Garau X, Klijanienko J: Fine-needle aspiration in myxofibrosarcoma: experience of Institut Curie. Diagn Cytopathol 2010;38:343-346.

-42 Kilpatrick SE, Ward WG: Myxofibrosarcoma of soft tissues: cytomorphologic analysis of a series. Diagn Cytopathol 1999;20:6-9.

-43 Kilpatrick SE, Ward WG, Bos GD: The value of fine-needle aspiration biopsy in the differential diagnosis of adult myxoid sarcoma. Cancer 2000;90:167-177.

-44 Konwaler B, Keasbey L, Kaplan L: Subcutaneous pseudosarcomatous fibromatosis (fasciitis). Am J Clin Pathol 1955;25:241-252.

45 Shimizu S, Hashimoto H, Enjoji M: Nodular fasciitis: an analysis of 250 patients. Pathology 1984;16:161-166.

46 Aydin O, Oztuna V, Polat A: Three cases of nodular fasciitis: primary diagnoses by fine needle aspiration cytology. Cytopathology 2001;12:346-347.

47 Kong CS, Cha I: Nodular fasciitis: diagnosis by fine needle aspiration biopsy. Acta Cytol 2004;48:473-477.

-48 Grosso F, Sanfilippo R, Virdis E, Piovesan C, Collini P, Dileo P, Morosi C, Tercero JC, Jimeno J, D’Incalci M, Gronchi A, Pilotti S,
Casali PG: Trabectedin in myxoid liposarcomas (MLS): a long-term analysis of a singleinstitution series. Ann Oncol 2009;20:14391444.

49 Conyers R, Young S, Thomas DM: Liposarcoma: molecular genetics and therapeutics. Sarcoma 2011;2011:483154.

50 Akerman M, Rydholm A: Aspiration cytology of lipomatous tumors: a 10-year experience at an orthopedic oncology center. Diagn Cytopathol 1987;3:295-302.

51 Fletcher CD, Akerman M, Dal Cin P, de Wever I, Mandahl N, Mertens F, Mitelman F, Rosai J, Rydholm A, Sciot R, Tallini G, van den Berghe H, van de Ven W, Vanni R, Willen H: Correlation between clinicopathological features and karyotype in lipomatous tumors. A report of 178 cases from the Chromosomes and Morphology (CHAMP) Collaborative Study Group. Am J Pathol 1996;148:623-630.

52 Eneroth M, Mandahl N, Heim S, Willén H, Rydholm A, Alberts KA, Mitelman F: Localization of the chromosomal breakpoints of the $\mathrm{t}(12 ; 16)$ in liposarcoma to subbands 12q13.3 and 16p11.2. Cancer Genet Cytogenet 1990;48:101-107.

53 Limon J, Turc-Carel C, Dal Cin P, Rao U, Sandberg AA: Recurrent chromosome translocations in liposarcoma. Cancer $\mathrm{Ge}$ net Cytogenet 1986;22:93-94.

54 Antonescu CR, Elahi A, Healey JH, Brennan MF, Lui MY, Lewis J, Jhanwar SC, Woodruff JM, Ladanyi M: Monoclonality of multifocal myxoid liposarcoma: confirmation by analysis of TLS-CHOP or EWS-CHOP rearrangements. Clin Cancer Res 2000;6:2788-2793.

55 Kubo T, Matsui Y, Naka N, Araki N, Myoui A, Endo K, Yasui N, Ohtani O, Suzuki K, Kimura T, Yoshikawa H, Ueda T: Specificity of fusion genes in adipocytic tumors. Anticancer Res 2010;30:661-664.

56 Guillou L, Aurias A: Soft tissue sarcomas with complex genomic profiles. Virchows Arch 2010;456:201-217.

57 Ohguri T, Hisaoka M, Kawauchi S, Sasaki K, Aoki T, Kanemitsu S, Matsuyama A, Korogi Y, Hashimoto H: Cytogenetic analysis of myxoid liposarcoma and myxofibrosarcoma by array-based comparative genomic hybridisation. J Clin Pathol 2006;59:978-983.

58 Bahrami A, Folpe AL: Adult-type fibrosarcoma: a reevaluation of 163 putative cases diagnosed at a single institution over a 48-year period. Am J Surg Pathol 2010;34:1504-1513.

59 Evans HL: Low-grade fibromyxoid sarcoma. A report of two metastasizing neoplasms having a deceptively benign appearance. Am J Clin Pathol 1987;88:615-619.

60 Lindberg GM, Maitra A, Gokaslan ST, Saboorian MH, Albores-Saavedra J: Low grade fibromyxoid sarcoma: fine-needle aspiration cytology with histologic, cytogenetic, immunohistochemical, and ultrastructural correlation. Cancer 1999;87:75-82.

61 Hollowood K, Fletcher CD: Soft tissue sarcomas that mimic benign lesions. Semin Diagn Pathol 1995;12:87-97.
-62 Reid R, de Silva MVC, Paterson L, Ryan E, Fisher C: Low-grade fibromyxoid sarcoma and hyalinizing spindle cell tumor with giant rosettes share a common $\mathrm{t}(7 ; 16)(\mathrm{q} 34 ; \mathrm{p} 11)$ translocation. Am J Surg Pathol 2003;27: 1229-1236.

-63 Patel RM, Downs-Kelly E, Dandekar MN, Fanburg-Smith JC, Billings SD, Tubbs RR, Goldblum JR: FUS (16p11) gene rearrangement as detected by fluorescence in-situ hybridization in cutaneous low-grade fibromyxoid sarcoma: a potential diagnostic tool. Am J Dermatopathol 2011;33:140-143.

64 Hinrichs SH, Jaramillo MA, Gumerlock PH, Gardner MB, Lewis JP, Freeman AE: Myxoid chondrosarcoma with a translocation involving chromosomes 9 and 22. Cancer Genet Cytogenet 1985;14:219-226.

65 Turc-Carel C, Dal Cin P, Sandberg AA: Nonrandom translocation in extraskeletal myxoid chondrosarcoma. Cancer Genet Cytogenet 1987;26:377.

-66 Sjögren H, Meis-Kindblom J, Kindblom LG, Aman P, Stenman G: Fusion of the EWS-related gene TAF2N to TEC in extraskeletal myxoid chondrosarcoma. Cancer Res 1999; 59:5064-5067.

67 Sjögren H, Wedell B, Meis-Kindblom JM, Kindblom LG, Stenman G, Kindblom JM: Fusion of the NH2-terminal domain of the basic helix-loop-helix protein TCF12 to TEC in extraskeletal myxoid chondrosarcoma with translocation $\mathrm{t}(9 ; 15)(\mathrm{q} 22 ; \mathrm{q} 21)$. Cancer Res 2000;60:6832-6835.

68 Tong G, Perle MA, Desai P, Kumar A, Waisman J: Parachordoma or chordoma periphericum? Case report of a tumor of the thoracic wall. Diagn Cytopathol 2003;29:1823.

69 Akerman M, Rydholm A: Aspiration cytology of intramuscular myxoma. A comparative clinical, cytologic and histologic study of ten cases. Acta Cytol 1983;27:505-510.

-70 Kim MR, Lee EH, Lee SE, Kwon JE, Lee KG, Kim YC, Kim S-C: Myxofibrosarcoma mimicking cutaneous myxoma. J Cutan Pathol 2010;37:1016-1018.

-71 van Roggen JF, McMenamin ME, Fletcher CD: Cellular myxoma of soft tissue: a clinicopathological study of 38 cases confirming indolent clinical behaviour. Histopathology 2001;39:287-297.

72 Okamoto S, Hisaoka M, Ushijima M, Nakahara S, Toyoshima S, Hashimoto H: Activating Gs(alpha) mutation in intramuscular myxomas with and without fibrous dysplasia of bone. Virchows Arch 2000;437:133-137.

73 Willems SM, Mohseny AB, Balog C, Sewrajsing R, Briaire-de Bruijn IH, Knijnenburg J, Cleton-Jansen A-M, Sciot R, Fletcher CDM, Deelder AM, Szuhai K, Hensbergen PJ, Hogendoorn PCW: Cellular/intramuscular myxoma and grade I myxofibrosarcoma are characterized by distinct genetic alterations and specific composition of their extracellular matrix. J Cell Mol Med 2009;13:12911301. 
74 Clarke LE, Zhang PJ, Crawford GH, Elenitsas R: Myxofibrosarcoma in the skin. J Cutan Pathol 2008;35:935-940.

75 Hornick JL, Fletcher CDM: Myoepithelial tumors of soft tissue: a clinicopathologic and immunohistochemical study of 101 cases with evaluation of prognostic parameters. Am J Surg Pathol 2003;27:1183-1196.

76 Capovilla M, Birembaut P: Primary cutaneous myxofibrosarcoma mimicking pleomorphic hyalinizing angiectatic tumor (PHAT): a potential diagnostic pitfall. Am J Dermatopathol 2006;28:276-277, author reply 277278.

77 Mitsuhashi T, Barr RJ, Machtinger LA, Cassarino DS: Primary cutaneous myxofibrosarcoma mimicking pleomorphic hyalinizing angiectatic tumor (PHAT): a potential diagnostic pitfall. Am J Dermatopathol 2005;27:322-326.

78 Kazakov DV, Pavlovsky M, Mukensnabl P, Michal M: Pleomorphic hyalinizing angiectatic tumor with a sarcomatous component recurring as high-grade myxofibrosarcoma. Pathol Int 2007;57:281-284.
79 Tardío JC, Martín-Fragueiro LM: Angiomyxolipoma (vascular myxolipoma) of subcutaneous tissue. Am J Dermatopathol 2004; 26:222-224.

80 Stephen MR, Morton R: Myxoid malignant fibrous histiocytoma mimicking papular mucinosis. Am J Dermatopathol 1998;20: 290-295.

81 Mansoor A, White CR: Myxofibrosarcoma presenting in the skin: clinicopathological features and differential diagnosis with cutaneous myxoid neoplasms. Am J Dermatopathol 2003;25:281-286.

82 Zelger BG, Steiner H, Wambacher B, Zelger $\mathrm{B}$ : Malignant melanomas simulating various types of soft tissue tumors. Dermatol Surg 1997;23:1047-1054.

83 Mentzel T, Brown LF, Dvorak HF, Kuhnen C, Stiller KJ, Katenkamp D, Fletcher CD: The association between tumour progression and vascularity in myxofibrosarcoma and myxoid/round cell liposarcoma. Virchows Arch 2001;438:13-22.
84 Fleshman R, Mayerson J, Wakely PE: Fineneedle aspiration biopsy of high-grade sarcoma: a report of 107 cases. Cancer 2007;111: 491-498.

85 Hollowood K, Fletcher CD: Malignant fibrous histiocytoma: morphologic pattern or pathologic entity? Semin Diagn Pathol 1995; 12:210-220

86 Downs-Kelly E, Goldblum JR, Patel RM, Weiss SW, Folpe AL, Mertens F, Hartke M, Tubbs RR, Skacel M: The utility of fluorescence in situ hybridization (FISH) in the diagnosis of myxoid soft tissue neoplasms. Am J Surg Pathol 2008;32:8-13.

87 Willems SM, Schrage YM, Baelde JJ, Briairede Bruijn I, Mohseny A, Sciot R, Bovée JVMG, Hogendoorn PCW: Myxoid tumours of soft tissue: the so-called myxoid extracellular matrix is heterogeneous in composition. Histopathology 2008;52:465-474.

88 Willems SM, Wiweger M, van Roggen JFG, Hogendoorn PCW: Running GAGs: myxoid matrix in tumor pathology revisited: what's in it for the pathologist? Virchows Arch 2010; 456:181-192. 